\title{
What a load of 'QoF'
}

\author{
Ghohonan Bugerem
}

Life has become all about collecting points. Fuel stations, supermarkets and, of course, credit cards all offer loyalty schemes to encourage us to spend more and claim our reward. After all, points make prizes don't they? And now even the National Health Service has got on board the points ship with the introduction of the new general practice contract and its very own loyalty scheme, the 'Quality and Outcomes Framework'. What a load of QoF this is.

All the major players are involved here: coronary heart disease (CHD), asthma, diabetes, for instance. All attract points but these patients are not easy to manage, are they? To begin with, they don't want to come to see you for their point-collecting check-ups. Even if you've strong-armed them into the surgery, they haven't been taking their medication since doing so leaves them with a dry mouth, or no libido, or both, which means that you don't get your points either. So these patients take a fair amount of work - of course that's why they've been included in the incentive scheme in the first place.

It's waxy ears, sore throats, thrush, and large pimples on the nose that I'd like to see in the scheme attracting points. These patients are always desperate to be seen and as regards cost-effectiveness, they are like taking candy from a baby. In fact, I wouldn't mind seeing these patients as the emergencies they claim to be, if they had nice fat points attached, and I'm not talking about the pimple that's now pointing, either.

Family planning patients - now here's a group of people I'd like to see included in the scheme. Wellbehaved women who act responsibly by coming along when asked and who offer me the chance to make some money. Sadly though, at present they don't really attract much money at all. A little pocket change under additional services and a miserly two points under QoF. One point for having a written policy for responding to requests for emergency contraception, for example: "staff are not to laugh and should refrain from saying "Better be more careful next time, eh" or "Serves you right, you filthy ...", the other for having a policy for providing preconceptual advice. But you get these points without even seeing a woman, so actually providing contraception doesn't bring you more points and is therefore really not very cost effective. It's hardly worth it, is it? But could it be made to pay?

Being well behaved is one thing, but having a chronic disease is really what these patients need if they're to bring the big money in. Yes, they can fill in a patient questionnaire about how wonderful you are, but we're still only talking minimal payback, points-wise that is. A screwdriver set or stainless thermos at most. Chronic disease is where the cars, boats and luxury holidays are. Think about this for a moment. Women are convinced that they gain weight on the pill despite this being due to fluid. If you don't waste time explaining the finer points about fluid retention and fat - time that could be spent chasing other points - your patient may well end up on the diabetes register. How? Like this. She believes her weight gain is down to the pill. So why challenge this, or her

J Fam Plann Reprod Health Care 2005; 31(2): 160

Pointsend, UK

Ghohonan Bugerem, General Practitioner subsequent belief that she may as well be inactive and overeat because there's nothing she can do to stop herself gaining weight anyway. Think of the knock-on effect of this. In time the obesity and diabetes will get her onto the CHD register too and the points will just pile up. I've heard that colleagues are already exploring this kind of financial strategy and suggesting that it's not beyond the realms of possibility for a woman on a high-dose regimen pill to develop high blood pressure, and subsequently join the stroke register too. They could barely contain their excitement as they rubbed their hands together, pound signs flashing before their eyes. But this was just coffee room larking about. No self-respecting general practitioner (GP) would even consider this ...

The reason why there's no real money to be made from family planning services may simply be a case of reverse psychology. You know how it works. I tell you not to do something so you immediately do it. In fact, abstinenceonly sex education programmes in Texas have recently demonstrated this point: more teenagers reported having had sex following their involvement in the programme than before taking part in it.

In fact, if we're honest with ourselves, the reason why there's no big money available from family planning in general practice is because the powers that be know that we GPs will do it anyway. Yes, we are the caring profession that is used to doing something for nothing, so why offer us an incentive to do something we are already doing? This, I'm sure, is the long-term plan with QoF. Once we're all doing it anyway there'll be no need to offer incentive points.

Here's my solution. I'm going to forget the patients and go shopping to enjoy some serious credit card retail therapy. Why? Because it's air miles I'm after, not points, so that I can fly away from all this nonsense and QoF.

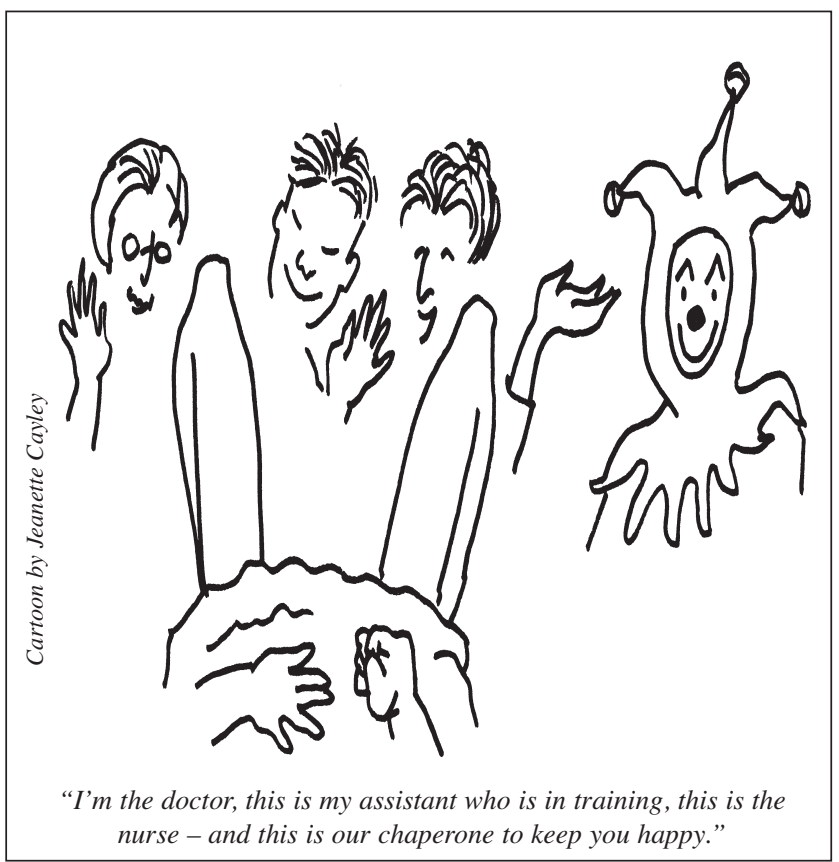

